Seminar Paper No. 198

INTERNATIONAL TRADE AND LABOR MIGRATION

$$
\text { by }
$$

Wilfred J. Ethier

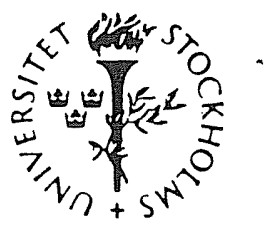

INSTITUTE FOR INTERNATIONAL ECONOMIC STUDIES

University of Stockholm 
ISSN $0347-8769$

Seminar Paper No. 198

INTERNATIONAL TRADE AND LABOR MIGRATION

by

Wilfred J. Ethier

Seminar Papers are preliminary material circulated to stimulate discussion and critical comment.

March, 1982

Institute for International Economic Studies S-106 91 Stockholm

Sweden 


\section{INTERNATIONAL TRADE AND LABOR MIGRATION}

Wilfred J. Ethier*

Foot-loose labor is prominent in the contemporary international economy. Migrant workers have accounted for up to a quarter of the Swiss labor force, and ten per cent of that of northern Europe generally. For years a number of European countries have administered formal guest-worker systems, and it has become commonplace to argue that such arrangements have helped insulate native populations from the rigors of industrial fluctuations and have also allowed the preservation of import-competing industries that would have succumbed completely to foreign competition without a supply of cheap migrant labor. A number of American industries now depend heavily upon migrant labor (both legal and illegal.) from Mexico and the Caribbean. South Asia supplies a large part of the labor for oil-financed Middle-Eastern economic development. Pakistan, for example, now earns almost three quarters as much foreign exchange from the remittances of temporary migrants abroad as from conventional exports; China has begun formally to contract the export of labor services. ${ }^{1}$

Although migrant labor has generated a large descriptive literature, formal economic treatment is scanty, especially in comparison with that accorded international capital movements. Two basic approaches may be noted. The first is concerned with the brain drain. The characteristic feature here is the coincidence of labor movements with that of human capital. Since the present paper is by contrast motivated by the large-scale movements of temporary migrants with few skills, I shall not allude further to this literature. 
The other approach has been simply to introduce international labor mobility into standard factor-endowment models of international trade. This results, for the most part, in treating migration symmetrically with international capital mobility. There can be no doubt that this approach is valuable. Useful insights have emerged, and the standard trade models have done all that can reasonably be asked of them. But at the same time certain central characteristics of contemporary experience are fundamentally alien to this approach.

At the risk of some oversimplification, one might isolate the following stylized facts as characteristic ${ }^{3}$ of a preponderant share of modern migration.

(i). Migration is regarded as temporary. Migrants typically intend to work abroad only long enough to accumulate nest eggs to establish themselves back home, and host countries typically issue temporary work permits. Although both sometimes discover that "you can't go home again," the common view of migration as temporary is a distinctive characteristic of its role in the host-country economy. The employment arrangements of native labor are by contrast generally regarded as much more permanent.

(ii). Migrant labor and native labor are imperfect substitutes in production. It is often said that migrants hold jobs which native workers would not accept, and this seems to be crucial to the political acceptance of immigration in host countries. But complete complementarity would preclude attempts to use migrants to shield native workers from the business cycle.

(iii). Migrants accept unpredictable variations in employment conditions more readily than do native workers. 
(iv). Migrant labor seems to be in practically unlimited supply at exogenously determined (but sometimes changing) terms. Once they have established connections with source-country labor pools, host countries generally experience little difficulty in recruiting all the migrants they are willing to accept. When changing conditions close off one source of supply, other sources are quickly found.

Although some of these characteristics can indeed be embodied into traditional trade models in quite straightforward fashion, others clearly cannot, and the four stylized facts on the whole describe a quite different world. Thus a new theoretical approach is needed. The present paper attempts to develop such a theory.

\section{International Equilibrium}

A. Migrant Labor and Traded Goods

A small country, call it Switzerland, specializes in the production of a single traded good, say chocolate. Chocolate is only a minor component of the Swiss consumption bundle: assume for simplicity that all chocolate is exported. These exports pay for imports of a composite traded good, which is consumed, and for the services of migrant labor.

Chocolate is produced by native labor and migrant labor, which are imperfect substitutes for each other. I assume that chocolate output is given by $D f(x)$, where $D$ denotes the employment of native labor, $x$ the ratio of migrant to native labor employed, and $f$ is a neoclassical production function (so that $\mathrm{f}^{\prime}>0$ and $\mathrm{f}^{\prime \prime}<0$ ).

Switzerland is too small to influence the relative prices of her imports, which can accordingly be treated as a single good, but the country is a sizable 
source of supply in the market for chocolate. Thus the price of chocolate (in terms of imports, i.e., Switzerland's commodity terms of trade) depends upon Swiss supply. It also depends upon the state of nature; for simplicity I assume there are only two possible states, each with probability one-half of occurrence. Thus equilibrium in each state is described by

$$
\begin{aligned}
& x_{A} g\left(P_{A}\right)=\operatorname{DD}\left(x_{A}\right) \\
& x_{B} g\left(P_{B}\right)=D E\left(x_{B}\right)
\end{aligned}
$$

A subscript refers to the state of nature, $g$ denotes the state-invariant component of world demand for Swiss chocolate, $x_{i}$ is the random variable, and $P_{i}$ denotes the price of Swiss chocolate in terms of the numeraire: imports. $D$ is the employment of native labor in state $B$, and e denotes the ratio of state A employment of natives to D. I label as A the state resulting in lower native employment, so $e \leq 1$.

The native labor market is characterized by a state-invariant wage and the possibility of layoffs once the state of nature becomes known. Migrant labor is in perfectly elastic supply at an exogenous (but possibly state-dependent) wage, and firms can decide their employment of migrants after the state of nature is realized. Firms maximize expected profit and so in each state hire migrants to ensure

$$
\begin{aligned}
& f^{\prime}\left(x_{A}\right)=v_{A} / P_{A} \\
& f^{\prime}\left(x_{B}\right)=v_{B} / P_{B}
\end{aligned}
$$

where $v_{i}$ denotes the exogenous migrant wage in state $i$.

Equations (2) and (4) jointly determine the state-B terms of trade $P_{B}$ and 
production technique $x_{B^{\prime}}$ provided that $D$ is given exogenously. Equations ( 1 ) and (3) yield a relation between $\mathrm{P}_{\mathrm{A}}, e$, and $\mathrm{x}_{\mathrm{A}}$. Solving out $\mathrm{x}_{\mathrm{A}}$ results in the II curve depicted in Figure $I$ below. This schedule shows those combinations of state-A terms of trade and relative native employment that clear international markets (goods' and migrant labor). The elasticity of this curve is

$$
\left.\frac{\mathrm{P}_{\mathrm{A}}}{\mathrm{e}} \frac{\mathrm{de}}{\mathrm{dP}}\right|_{\mathrm{A}}=-\frac{\rho_{\mathrm{A}}}{I-\theta_{\mathrm{MA}}} .
$$

In this expression $\rho_{\mathrm{A}}=\theta_{\mathrm{MA}} \sigma_{\mathrm{A}}+\left(1-\theta_{\mathrm{MA}}\right) \eta_{\mathrm{A}}$, where $\sigma_{i}, \eta_{i}$ and $\theta_{M i}$ respectively denote state-i elasticity of substitution between native and migrant labor $\left(-f^{\prime}\left(x_{i}\right)\left[1-\left(x_{i} f^{\prime}\left(x_{i}\right) / f\left(x_{i}\right)\right)\right] / x_{i} f^{\prime \prime}\left(x_{i}\right)\right)$, elasticity of demand for Swiss chocolate $\left(-P_{i} g^{\prime}\left(P_{i}\right) / g\left(P_{i}\right)\right)$, and migrant labor's distributive share $\left(x_{i} f^{\prime}\left(x_{i}\right) / f\left(x_{i}\right)\right)$.

Low values of e indicate high volatility of native employment across states. Low values of $\mathrm{P}_{\mathrm{A}}$ will likewise indicate high volatility of the terms of trade, if $\mathrm{P}_{\mathrm{A}}<\mathrm{P}_{\mathrm{B}}-$ - a situation subsequent analysis will reveal to be "normal" though not inevitable. In such a case the II curve depicts a tradeoff between employment volatility and terms-of-trade volatility that is presented to switzerland by the international economy. High elasticities -- of both demand and substitution -- imply a high (in absolute value) elasticity of the II curve: the acceptance of some increased volatility in the terms of trade will significantly reduce the volatility of domestic employment. Also an increased prominence of migrant labor (in the sense of a larger $\theta_{M A}$ ) implies a higher II elasticity, with the increase in the latter sensitive to the ease of substituting native labor for foreign, that is, the magnitude of $\sigma_{\mathrm{A}}$. In any event, the point on the II tradeoff which Switzerland actually experiences depends upon the behavior of the native labor market, to which I now turn. 


\section{B. The Native Labor Market}

A native worker hired by a chocolate firm has an assured job in state $B$ and the probability $e$ of a job in state $A$; he receives the wage $w$ if employed. Domestic labor unemployed in the chocolate industry produces traded goods, with constant average productivity $\mathrm{W}$, for its own consumption. Thus in state A a domestic worker receives ${ }^{4}$ with probability $e$ and $W$ with probability i-e. Workers are risk averse with the utility function $u=u(w, e)$ over implicit contracts (w,e). The typical firm chooses a wage and the employment of each type of labor in each state so as to maximize expected profit, given the exogenous $v_{A}$ and $v_{B}$ and the market-determined $P_{A}, P_{B}$ and $u$. Competition among native workers for implicit contracts causes u to adjust so that employment of natives in state $B$ equals $D$, the domestic labor force.

Suppose that the market for natives is in equilibrium, and consider the possibility of a marginal increase in state-A employment $\mathrm{eD}$ (that is, a marginal decrease in lay offs) by a typical chocolate firm, given the level of state-B employment. If each state has probability one-half of occurrence, such an increase would raise expected revenues by $P_{A}\left[f\left(x_{A}\right)-x_{A} f^{\prime}\left(x_{A}\right)\right] / 2$. The expected wage payment to the no-longer-laid-off worker is $w / 2$. But the increase in e makes employment at this firm more attractive because it is more secure: the probability of any worker retaining his job in state $\mathrm{A}$ has risen. Thus this firm can reduce its wage to all workers and remain competitive, that is, keep $\mathrm{u}(\mathrm{w}, \mathrm{e})$ unaltered. Let $\mathrm{V}(\mathrm{w}, \mathrm{e})$ denote a worker's marginal rate of substitution of $w$ for e (i.e., $\left.u_{2} / u_{1}\right)$. Then the expected reduction of the firm's wage bill for this reason is D V (w, e) $\frac{d e}{d(e D)}\left(\frac{1}{2}+\frac{e}{2}\right)=\frac{1}{2} V(1+e)$. In equilibrium expected revenue must rise the same amount as expected wage payments, so that 
(5)

$$
w=P_{A}\left[f\left(x_{A}\right)-x_{A} f^{\prime}\left(x_{A}\right)\right]+(1+e) V \cdot(w, e) .
$$

In like manner, consideration of the possibility of a marginal increase in state-B employment $D$, for a given level of state-A employment $e D$, yields the additional equilibrium condition

$$
w=P_{B}\left[f\left(x_{B}\right)-x_{B} f^{\prime}\left(x_{B}\right)\right]-e(1+e) V(w, e) .
$$

Full equilibrium is described by (1) - (6) which solve for $P_{A}, P_{B}, x_{A}, x_{B}$, w and $e$, given the values of $x_{A}, X_{B}, v_{A}, v_{B}$ and $D$. This equilibrium is shown

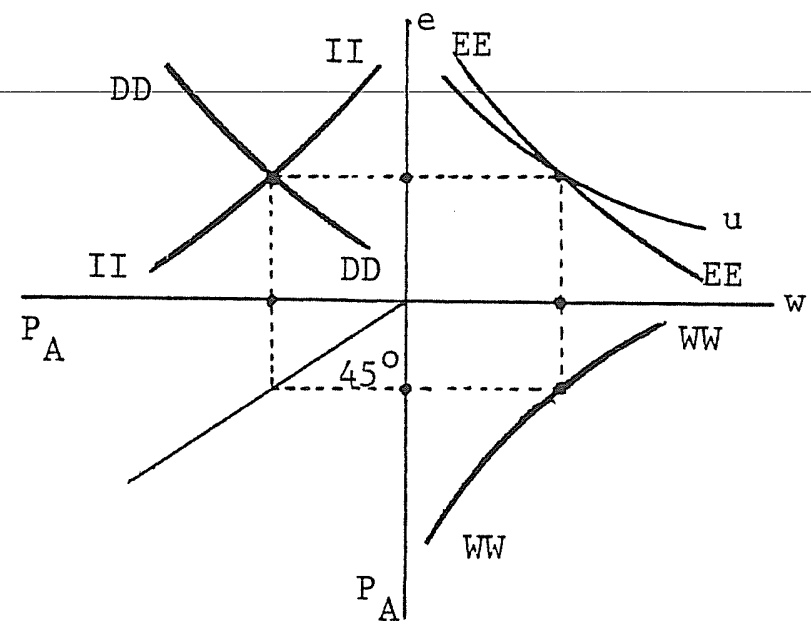

Figure 1. International Equilibrium

in Figure 1.

The WW schedule in the figure shows for each state-A terms of trade the native wage rate consistent with equilibrium in the domestic factor markets. This curve comes from (3) and. (5), which give

$$
\frac{\partial \mathrm{w}}{\partial \mathrm{P}_{\mathrm{A}}}=\frac{-f\left(\mathrm{x}_{\mathrm{A}}\right)}{(1+e) V_{\mathrm{W}}-1} ; \quad \frac{\partial_{\mathrm{w}}}{\partial \mathrm{e}}=\frac{(1+e) V_{e}+V}{1-(1+e) V_{\mathrm{W}}}
$$


It is convenient to make the following assumptions. 5

$$
\begin{aligned}
& (I+e) V_{W}>I \\
& (I+e) V_{e}=-V .
\end{aligned}
$$

These assumptions assure that WW is independent of $\bar{e}$ and slopes in the direction indicated in the figure. From (6) we have a further relation, the EE schedule in Figure 1. This curve slopes down more steeply than do the indifference curves of native workers. Thus a movement downwards and to the right along EE reduces the welfare of native workers, even though their wages rise, because of the detrimental effect on job security. By using the EE and WW schedules together, as in Figure 1, I can trace out for each $P_{A}$ the value of e consistent with domestic equilibrium. This is done and recorded as the DD schedule. Full equilibrium is then determined by the intersection of the II and DD curves. The equilibrium values of $P_{A^{\prime}}$ e and $w$ can be read off of the figure, and then $\mathrm{x}_{\mathrm{A}}$ is determined by (3); $\mathrm{P}_{B}$ and $\mathrm{x}_{\mathrm{B}}$ are independently determined by (2) and (4). The Swiss populace is exposed to uncertainty through both of the:international markets in which it deals. Risk neutral firms provide partial insulation from this uncertainty. The insulation they can provide is in turn related in two ways to their own activity on world markets. By hiring foreign workers in good times and discharging them in bad times, firms help insulate swiss workers. The second method has to do with the pricing of chocolate. Equation (1) says that in state A firms pay migrants the value of their marginal product, and (3) says that Swiss workers are paid more than the value of their marginal product. Thus Switzerland exports chocolate at a price less than its cost of production, that is Swiss products are dumped ${ }^{6}$ in world markets in state A. Note that this dumping would appear aggressive to foreign competitors, since Swiss firms employ no fixed factors at all but dump in order to avoid laying off workers. 
Chocolate is sold above cost in state $B$, so that firms expect to break even in the long run (I assume that firms hold an inventory of traded goods -- a Wages Fund -- to pay their workers).

The expulsion of foreign workers and the dumping of commodities has each received great attention throughout the previous decade, but the relation between the two has been largely ignored. The present paper offers a framework for the investigation of this relationship.

The Swiss economy is exposed to uncertainty through the two international markets in which it deals. This paper will not directly examine economic policy, so it is important to point out that the stochastic process relating to labor migration -- reflected in the m agnitudes of $v_{A}$ and $v_{B}$-- would in practice be quite sensitive to national immigration policy. For example, a guest worker system might be operated in a relatively closed fashion, allowing only a modest volume of immigration and adjusting that in response to disturbances so as to stabilize the migrant wage faced by individual domestic firms. Alternatively the authorities might be more willing to allow the domestic economy to exploit the opportunity to obtain cheap migrant labor services and so operate a more open guest worker system, insisting that all migrants have jobs but not trying to shield chocolate firms from external fluctuations in migrant wages. The authorities might also vary their administration of a guest worker system in response to fluctuations in the world demand for chocolate. This diversity of possibilities demands an investigation of how economic performance varies in response to changes in the stochastic process facing Switzerland. I turn next to this problem. 
II. Dumping Goods and Dumping Migrants

This section examines how Swiss activity in the two international markets relates to the nature of the stochastic process facing the country. Take $\mathrm{X}_{\mathrm{B}}$ and $v_{B}$ as immutable (so that equilibrium values of $x_{B}$ and $P_{B}$ do not change, from (2) and (4)) and consider alternative values of $\mathrm{x}_{\mathrm{A}}$ and $\mathrm{v}_{\mathrm{A}}$. Each pair of valiues determines equilibrium levels of $P_{A^{\prime}}, e, w$, and $x_{A^{\prime}}$ from (1), (3), (5) and (5). Each point in the quadrant of each panel of Figure 2 below thus corresponds to a distinct hypothetical stochastic process confronting Switzerland. At point $C, x_{A}=x_{B}$ and $v_{A}=v_{B}$, so that the future is certain. Thus both states have identical, full-employment equilibria: $P_{A}=P_{B}$ and $e=1$. Employment of migrants also does not vary across states, so that $\mathrm{m}=1$, where $\mathrm{m}$ denotes the ratio of state-A employment of migrants to state-B employment, and thus $m \equiv \operatorname{ex}_{A} / x_{B}$. At $C$ the present $m o d e l$ in effect reduces to the standard factor endownents model with complete specialization in the production of exportables.

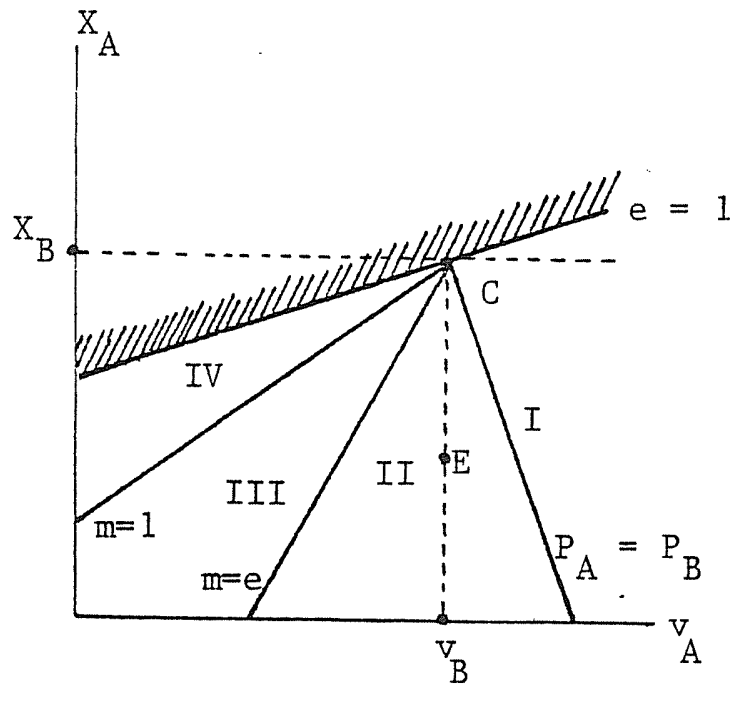

(a) $\eta_{\mathrm{A}}>\sigma_{\mathrm{A}}$

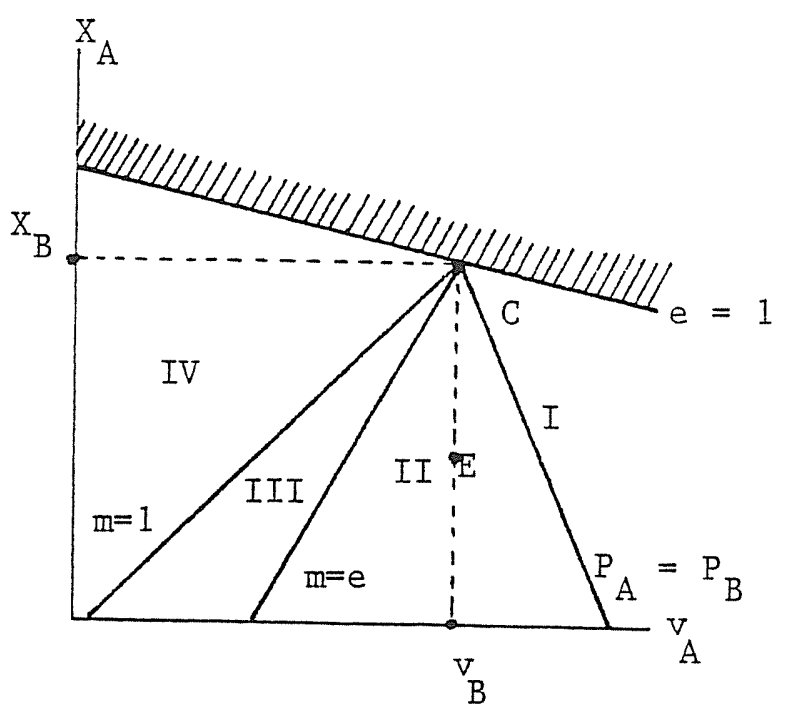

(b) $\eta_{A}<\sigma_{A}$

Figure 2. Possible Outcomes 
Each pair of values of $\mathrm{x}_{\mathrm{A}}$ and $\mathrm{v}_{\mathrm{A}}$ determines, from equations (1), (3), (5) and (6), equilibrium values of $m, e, P_{A}$ and $w$. I shall examine in turn the effects of variations in $x_{A}$ and $v_{A}$ upon equilibrium. Consider, first, a rise in $x_{A}$ in the proportion $\hat{x}_{A}$. For any given value of $P_{A^{\prime}} x_{A}$ is unchanged, from (3). Thus from (1), $\hat{e}=\hat{x}_{A}$, where a circumflex denotes proportional change; i.e., the II curve in Figure $I$ shifts upwards in proportion to the rise in $\mathrm{X}_{\mathrm{A}^{\prime}}$ reflecting the fact that higher state-A demand for chocolate at each price allows more native employment (as well as more migrant employment). As is evident from the figure, this produces a rise in both $\mathrm{P}_{\mathrm{A}}$ and $\mathrm{e}$. The wage falls, but not by enough to cancel out the benefit of increased job security, since the resulting movement along the EE schedule leads to a higher indifference curve. The increase in $\mathrm{X}_{\mathrm{A}}$ actually makes the Swiss worse off should state $\mathrm{B}$ materialize -- $\mathrm{w}$ falls and everyone is employed in any case -- to more fully concentrate the benefits in state A. Note from Figure 2 that for most (but not all) initial states below the $e=1$ line (explained soon), a rise in $\mathrm{x}_{\mathrm{A}}$ brings it closer to $\mathrm{X}_{\mathrm{B}}$ : not only does expected demand rise, fluctuations are also damped.

Suppose next that $\mathrm{v}_{\mathrm{A}}$ increases in the proportion $\hat{\mathrm{v}}_{\mathrm{A}}$. For a given $\mathrm{P}_{\mathrm{A}^{\prime}}, \mathrm{x}_{\mathrm{A}}$. must fall, from (3), in a proportion sensitive to the elasticity of substitution between domestic and foreign laborers. This increases e, from (I), so that the II schedule again shifts up, but this time the shift reflects a substitution of domestic workers for foreign at each price. The fall in $\mathrm{x}_{\mathrm{A}}$ must also, at given $\mathrm{P}_{\mathrm{A}}$, increase $\mathrm{w}$, from (5), thereby shifting the WW schedule to the right. This implies that DD shifts down. The net effect of the rise in $\mathrm{v}_{\mathrm{A}}$ is therefore ambiguous with respect to $\mathrm{e}$, while $\mathrm{P}_{\mathrm{A}}$ necessarily rises (but by less than $\mathrm{v}_{\mathrm{A}}$ ). The direction of change of e clearly depends upon the relative slopes of the II and DD curves, as well as upon the magnitude of the shift of the former. That magnitude is sensitive to $\sigma_{\mathrm{A}}$ whereas the slope of 
the II curve also depends upon $\eta_{A^{*}}$. It's not surprising, then, that e rises or falls according as $\sigma_{A}>n_{A}$ or not. 8

The $e=1$ lines in Figure 2 show the stochastic assumptions yielding equilibrium full employment of Swiss workers in both states. The curve is derived by setting $e=I$ in (1), (3), (5) and (6) and solving for $x_{A}$ as a function of $v_{A}$ (the algebra for all the curves in Figure 2 may be found in the Appendix). Below this line $e<1$, and all points above the line are ruled out by assumption, since $e>1$ there -- points above the line simply duplicate the possibilities represented below the line with the roles of the two states reversed. Since I have just shown that a rise in $\mathrm{x}_{\mathrm{A}}$ increases $\mathrm{e}$ whereas a rise in $\mathrm{v}_{\mathrm{A}}$ has an ambiguous effect, the-e- $=1$ line has a positive or negative slope-depending upon whether a rise in $\mathrm{v}_{\mathrm{A}}$ reduces or increases e. As one would expect, this depends upon the relative strength of the elasticities of demand and substitution.

The line labelled $\mathrm{P}_{\mathrm{A}}=\mathrm{P}_{\mathrm{B}}$ shows the assumptions that result in sticky commodity prices across states. This line has a negative slope because, as we have seen, $\mathrm{P}_{\mathrm{A}}$ is increased by rises in both $\mathrm{X}_{\mathrm{A}}$ and $\mathrm{v}_{\mathrm{A}}$. The line labelled $\mathrm{m}=1$, where the employment of migrants is constant across states, is found by solving (1), (3), (5) and (6) for $\mathrm{x}_{\mathrm{A}}$ as a function of $\mathrm{v}_{\mathrm{A}}$ subject to the restriction that $\mathrm{ex}_{\mathrm{A}}=\mathrm{x}_{\mathrm{B}}$. This curve has a positive slope because an increase in $\mathrm{x}_{\mathrm{A}}$ increases both $\mathrm{e}$ and $\mathrm{x}_{\mathrm{A}}$ and must therefore be accompanied by a rise in $\mathrm{v}_{\mathrm{A}}$, which has a modest effect on e but necessarily reduces $\mathrm{x}_{\mathrm{A}}$ (by raising $\mathrm{P}_{\mathrm{A}}$ less than $\left.v_{A}\right)$. Finally, setting $x_{A}=x_{B}$ in the equations of equilibrium and solving for $\mathrm{X}_{\mathrm{A}}$ as a function of $\mathrm{v}_{\mathrm{A}}$ yields those combinations where Swiss employment varies in the same proportion as migrant employment: $\mathrm{m}=\mathrm{e}$. An increase in $\mathrm{v}_{\mathrm{A}}$ raises $\mathrm{P}_{\mathrm{A}}$ in lesser proportion, and so must be accompanied by a rise in $x_{A}$ to keep $v_{A} / P_{A}$, and thus $x_{A}$, unchanged. Hence the $m=e$ curve also has a positive slope. These four lines determine four distinct zones of possibilities, whose properties are summarized in Table 1. 


\begin{tabular}{|c|c|c|}
\hline Zone & Employment & Terms of Trade \\
\hline I & I $>\mathrm{e}>\mathrm{m}$ & $\mathrm{P}_{\mathrm{A}}>\mathrm{P}_{\mathrm{B}}$ \\
II & $1>\mathrm{e}>\mathrm{m}$ & $\mathrm{P}_{\mathrm{A}}<\mathrm{P}_{\mathrm{B}}$ \\
III & $1>\mathrm{m}>\mathrm{e}$ & $\mathrm{P}_{\mathrm{A}}<\mathrm{P}_{\mathrm{B}}$ \\
IV & $\mathrm{m}>\mathrm{I}>\mathrm{e}$ & $\mathrm{P}_{\mathrm{A}}<\mathrm{P}_{\mathrm{B}}$ \\
\hline
\end{tabular}

Table 1. Possible Equilibria

Suppose initially that $\mathrm{v}_{A}=\mathrm{v}_{\mathrm{B}}$, as at points $\mathrm{E}$ in Figure 2. Then Switzerland is exposed to uncertainty solely through the chocolate market. As is clear from the figure, this necessarily results in a zone II equilibrium. Whenever the unfavorable state A materializes, Swiss workers are laid off $(e<1)$. But Swiss firms moderate this in two ways: they reduce prices $\left(P_{A}<P_{B}\right)$ and dump chocolate abroad, and they also lay off migrant workers in greater proportion than Swiss workers $(m<e)$. Thus both chocolate and migrants are dumped abroad when foreign demand for Swiss goods falls. Zone II equilibria would characterize guest worker systems administered in a "closed" way as discussed in section 1 above.

Now let $\mathrm{v}_{\mathrm{A}}$ fall, that is, consider left-ward movements in Figure 2. This consists of cases where low values of $\mathrm{X}_{i}$ are accompanied by low values of $v_{i}$ : unfavorable commodity-market conditions are correlated with favorable labor-market conditions. This would be the case if Swiss chocolate, and its close substitutes, were to a large degree sold in the same countries from which migrant labor comes : both conditions would be sensitive to aggregate demand in those countries. Such movements depart further from the $\mathrm{P}_{A}=\mathrm{P}_{B}$ line in Figure 2, implying larger state-A price reductions in chocolate to stimulate demand. This is made possible by the cost-reducing effect of lower values of $\mathrm{v}_{\mathrm{A}}$. The latter also furnishes a motive to reduce fluctuations in the employment of migrants, and $m$ indeed rises with leftward movements in Fugure 2. Thus 
domestic employment is tugged in two directions by the tendency, on the one hand, to substitute foreign workers for domestic workers in state A -- made easier by higher values of $\sigma_{\mathrm{A}}--$ and by the tendency, on the other, to increase state A production -- made easier by higher values of $\eta_{A}$-- which affects foreign and migrant employment in a complementary way. If Switzerland is basically a small country in the world chocolate market (very large $\eta_{A}$ ) the complementarity aspect necessarily dominates, but with less than infinite elasticity of demand the opportunity to expand chocolate sales is limited. In general the complementarity or the substitutability aspect will dominate according as $\eta_{A}>\sigma_{A}$ or the reverse, since Figure 2 shows that this is the condition deciding whether a leftward movement of $\mathrm{v}_{\mathrm{A}}$ approaches or departs further from the $e=1$ line.

If $v_{A}$ falls enough the economy finds itself in zone III where migrant employment is more stable than domestic employment. But migrants are still being used to stabilize Swiss employment conditions: since migrant wages fall when the demand for chocolate falls, retaining more foreign workers on the payroll in state A reduces costs and may still allow more Swiss workers to be retained also, if $\eta_{\mathrm{A}}>\sigma_{\mathrm{A}}$. If chocolate conditions and foreign labor conditions are sufficiently negatively correlated, the economy will be in zone IV, so that employment of migrants actually rises in state A. Chocolate-dumping and migrant-dumping cease to be complementary and become substitutes: chocolate is dumped in state $\mathrm{A}$ and migrants in state $\mathrm{B}$. It could also become unclear whether the migrant labor market is being exploited to shield Switzerland from shocks in the chocolate market, or whether the reverse is the case. For example, if $\eta_{A}<\sigma_{A}$ zone IV will contain cases where $x_{A}>x_{B}$ and $v_{A}<v_{B}$ : in state A domestic unemployment due to the substitution of cheap migrant labor is ameliorated by an increased foreign demand for chocolate. In any event the dumping of chocolate that takes place in state A would seem very aggressive indeed to Switzerland's foreign competitors; the Swiss increase their employment of migrants to be able to dump chocolate abroad! 
Positions to the right of point $\mathrm{E}$ in Figure 2 correspond to cases where favorable commodity conditions are positively correlated with favorable (for the Swiss) migrant labor conditions. This could be the case if chocolate is sold in a part of the world with economic conditions negatively correlated with those in the part of the world from which the migrants come. Since labor costs rise in state $A$, the Swiss are less able to reduce prices, though they still dump chocolate. Instead they are more inclined to lay off migrants and substitute domestic labor: e > m to the right of $\mathrm{E}$. If $\sigma_{\mathrm{A}}>\eta_{\mathrm{A}}$ this substitution effect will outweigh the complementarity effect resulting from the depressing influence of higher costs, and the increase in $\mathrm{v}_{\mathrm{A}}$ will move the Swiss-closer to the e = I-Iine. With high enough positive correlation between chocolate and migrant labor conditions, Switzerland will be in zone I, characterized by the apparent paradox that the Swiss increase the price of chocolate when they dump it $\left(\mathrm{P}_{\mathrm{A}}>\mathrm{P}_{\mathrm{B}}\right)$. The reason is simply that they raise prices to cover part, but not all, of their increased labor costs.

Public discussion of labor migration emphasizes two, basically inconsistent, alleged benefits to host countries: isolation of native workers from the business cycle by varying the employment of migrants (which requires a substitutability of domestic and foreign labor in production), and preservation of domestic jobs in domestic industries by reliance on cheap migrant labor (which emphasizes 
complementarity). The present analysis provides a framework for the study of these two alleged benefits and shows how they relate to the nature of the stochastic process facing the host country, as well as to basic parameters such as elasticities of demand and of substitution (which determine the shape and position of the curves in Figure 2). The dividing line between the two cases is the $m=e$ curve, the locus of possibilities for which production techniques are unchanged across states. In zones I and II the Swiss respond to a recession by substituting domestic workers for migrants and sending the latter home: the recession is (partly) passed on to foreign workers. In zones III and IV a recession by contrast causes migrants to be substituted for domestic labor, and it is the resulting cost reduction which allows larger chocolate production - and native employment - - than would otherwise be possible. This latter possibility requires, but is not assured by, a negative correlation between conditions in the two markets. A higher elasticity of chocolate demand increases the ability of a price reduction - - - and thus cost reduction - - - to maintain chocolate output. Thus larger values of $n_{A}$ cause the $m=e$ line to become steeper (this is confirmed in the Appendix) and so expands zones III and IV at the expanse of I and II. But, unless $\eta_{A}$ is infinite, zone II necessarily contains cases where $\mathrm{V}_{\mathrm{A}}<\mathrm{V}_{\mathrm{B}}$.

The parameter $\sigma_{A}$ measures the extent to which domestic and migrant labor are similar and thus highly substitutable for each other. As $\sigma_{\mathrm{A}}$ increases, zone IV expands at the expense of the other three zones. 
Note that fluctuations in native Swiss employment are never removed completely, unless the country just happens to face a stochastic process directly on the $e=1$ line. Only then can some combination of chocolate dumping and migrant dumping be found to totally stabilize Swiss employment.

\section{Some Comparative Statics}

In this section I investigate how the Swiss equilibrium responds to changes in some of the key determinants identified by the present theory. Changes in the stochastic process will not be discussed, because they can be viewed as simply movements in Figure 2. Consider first a general improvement in the opportunity to hire migrants: an equiproportional fall in $\mathrm{v}_{\mathrm{A}}$ and $\mathrm{v}_{\mathrm{B}}$.

The discussion in the previous section implies that the fall in $v_{A}$ shifts the II schedule down and the WW schedule to the left, as shown in Figure 3 below. The fall in $v_{B}$ would raise $x_{B}$, at constant $P_{B}$, from $(4)$. This would produce an excess supply of chocolate in state B, from (2). A fall in $P_{B}$ would moderate the rise in $x_{B}$ and also increase chocolate demand. Thus the fall in $v_{B}$ necessarily reduces $P_{B}$ in smaller proportion and increases $\mathrm{x}_{B}$ : the Swiss respond to the lower migrant wage by hiring more migrants in the favorable state and thereby turning the chocolate terms of trade against themselves. From equation (6) it is evident that the EE schedule will shift to the right or the left according as $P_{B}\left[f\left(x_{B}\right)-x_{B} f^{\prime}\left(x_{B}\right)\right]$, the marginal value product of Swiss workers, rises or falls. Differentiating this term and substitution from (2) and (4) yields

$$
\frac{d\left(P_{B}\left[f\left(x_{B}\right)-x_{B} f^{\prime}\left(x_{B}\right)\right]\right)}{d v_{B}}=\frac{x_{B} \theta_{D B}}{\rho_{B}}\left[\sigma_{B}-\eta_{B}\right] \text {, }
$$


where $\theta_{D i}=1-\theta_{M i}$ and $\rho_{i}=\theta_{M i} \sigma_{i}+\theta_{D i} n_{i}$. Thus the marginal value product of Swiss workers rises or falls according as the elasticity of substitution exceeds or falls short of the elasticity of demand. For ease of illustration I have assumed in Figure 3 that $\sigma_{B}=\eta_{B}$, so that the EE schedule stays put.

The left-ward shift of WW accordingly produces, in the figure, an upward shift of DD. The net effect of the shifts in II and DD is evidently ambiguous. For simplicity, Figure 3 shows the special case where these two curves shift in such a way as to move their intersection horizontally to the right. In this case $e$ and $w$ do not change. Chocolate firms increase their state-A employment of migrants (in the same proportion as state-B employment). Native workers are employed in the same numbers as before in each state and receive the same wage: the increased employment of migrants and the worsened terms of trade just cancel the effect of lower migrant wages on expected revenues. The utility of Swiss workers does not change and the nation receives no benefit from the lower cost of foreign workers. Evidently alternative circumstances could lead to movements in either direction along the EE schedule, and

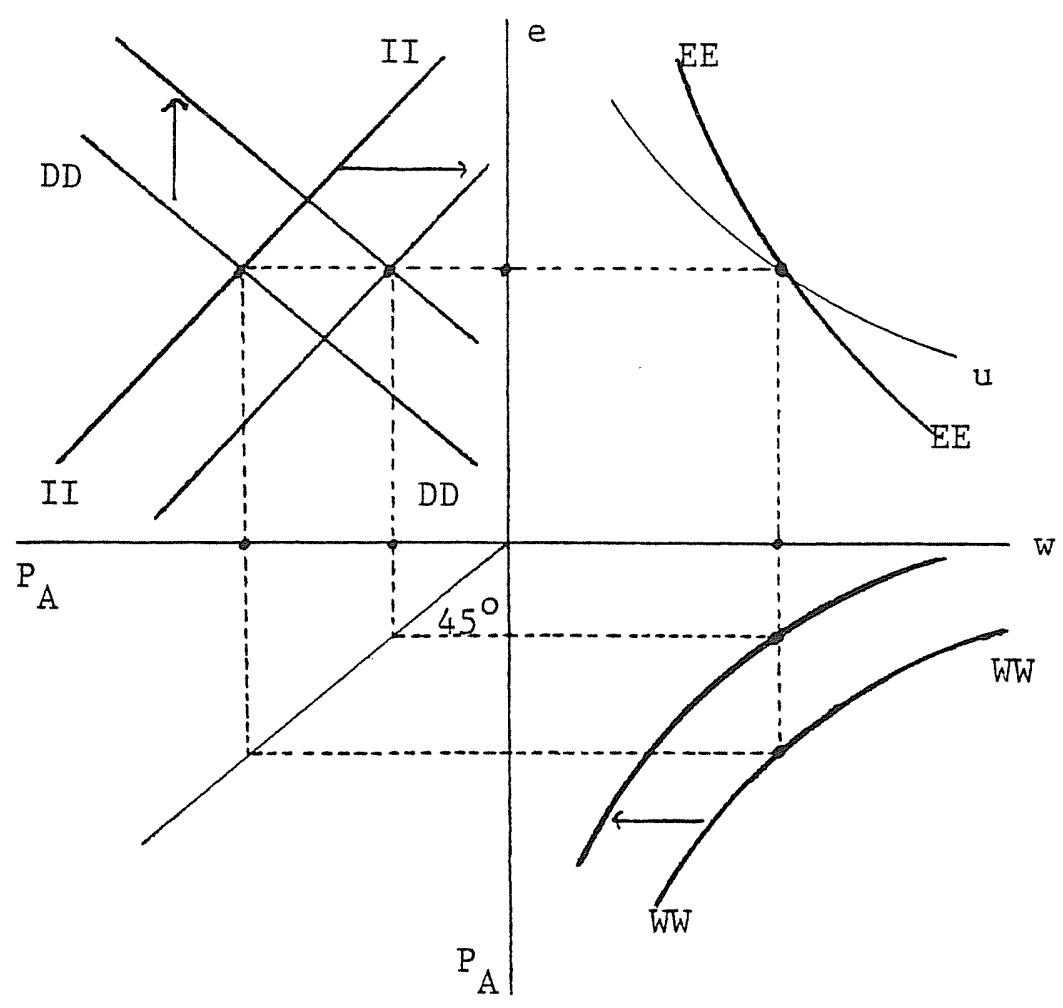

Figure 3. A Fall in Migrant Wages (Special Case) 
therefore move the country to either higher or lower indifference curves: the opportunity to hire migrant workers at lower wages could actually make the Swiss worse off! Such "immiserizing growth" might in this model be due to either or both of two distinct causes: the absence of an optimal export tax on chocolate and the incompleteness of markets to deal with risk. ${ }^{8}$

Thus far I have focused on how domestic employment opportunities are related to international markets. But clearly they are also related to $\mathrm{W}$, the reward that can be earned by Swiss workers who lose their jobs in the chocolate industry. A rise in $\mathrm{W}$ makes such a job loss less onerous and therefore reduces $V$, the wage rise necessary to compensate for an increased probability of unemployment. Let $\lambda_{W}=W_{W} / V<0$, the elasticity of $V$ with respect to $W$. Consider a rise in W. Equations (5) and (6) imply that the WW and EE schedules both shift to the right. It is then apparent from Figure 1 that DD will shift up or down depending upon whether EE shifts more or less than does WW.

Differentiation of (5) reveals the shift in $\mathrm{EE}$,

$$
\hat{w}=-\frac{\left(\theta_{D B}-\mu_{D B}\right)}{\gamma_{B}} \lambda_{W} \hat{W}
$$

while differentiation of (6) does the same for WW,

$$
\hat{\omega}=\frac{\mu_{\mathrm{DA}}-{ }_{\mathrm{DA}}}{\gamma_{\mathrm{A}}} \lambda_{\mathrm{W}} \hat{\mathrm{W}} \quad[\mathrm{WW}],
$$

where $\mu_{D i}=w_{i} P_{i}\left(x_{i}\right), \gamma_{i}=\lambda \theta_{D i}+(1-\lambda) \mu_{D i}$, and $\lambda=V_{w} w / V$. Now $\theta_{D i}$ denotes what domestic labor's share of chocolate output would be in state $i$ if it were paid the value of its marginal product, whereas $\mu_{D i}$ denotes the actual share of Swiss workers. Therefore $\mu_{D A}>\theta_{D A}$ and $\mu_{D B}<\theta_{D B}$, which in turn implies that $\gamma_{B}>0$. Also (A1) and (A2) imply that $\gamma_{A}<0$. Thus (7) 
and (8) confirm that $\mathrm{EE}$ and WW both shift to the right. Also subtraction of (7) from (8), and a little manipulation, reveals that WW must shift proportionally more, because

$$
\frac{\mu_{D A}}{\mu_{D B}}>\frac{{ }^{{ }_{D A}}}{{ }^{{ }_{D B}}}
$$

Figure 4 shows the effect of a rise in $W$ on Swiss equilibrium. Wages rise and e falls, the expected response to making unemployment less unpalatable. Equations (2) and (4) show that, in the favorable state, the employment of migrants, as well as natives, is unchanged, so that the terms of trade are unaltered also. The only modification is a higher wage for the entire native labor force. As seen in Figure 4, $\mathrm{P}_{\mathrm{A}}$ rises so that the increase in $W$ reduces price fluctuations - - - unless the equilibrium is in zone I,

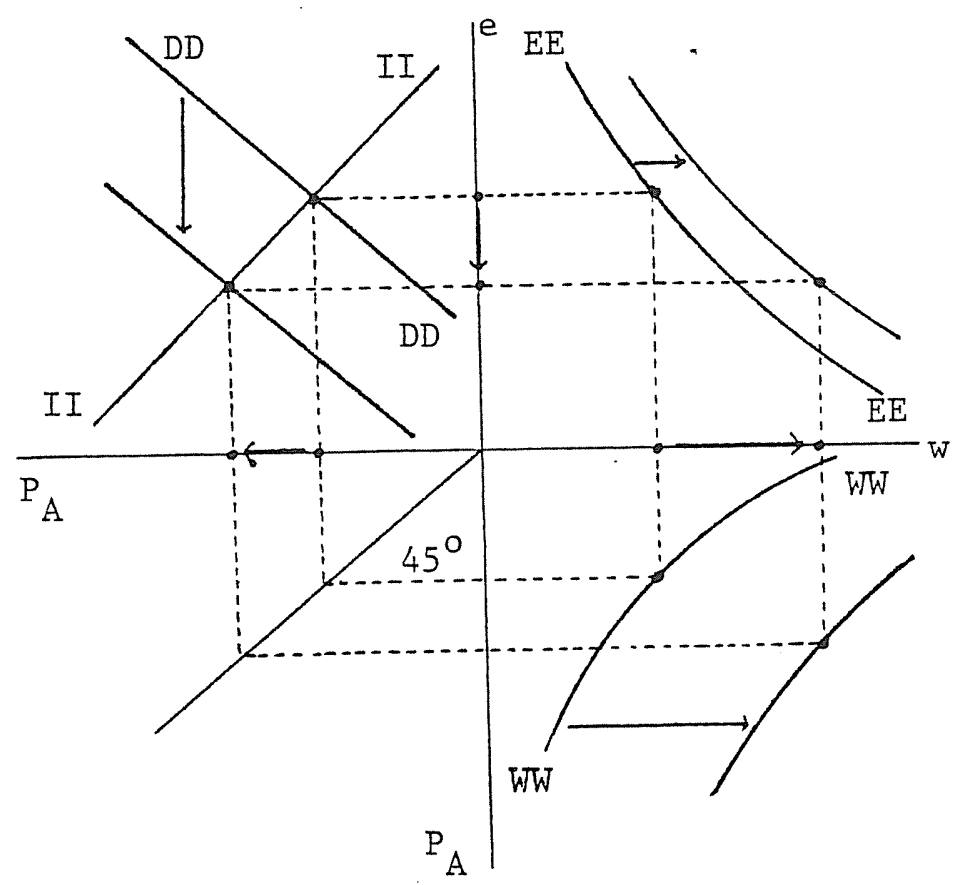

Figure 4. An Increase in W. 
where the effect is perverse. The better state-A terms of trade help finance the higher wage and so moderate the necessary reduction in e. Also $\mathrm{x}_{\mathrm{A}}$ rises, so that state-A employment of migrants rises relative to that of natives; thus the rise in $W$ reduces fluctuations in migrant employment compared to native employment (except possibly if the equilibrium is in zone IV.). But the absolute volume of migrant employment in state A may either rise or fall. Since native labor has become relatively more expensive, a high elasticity of substitution promotes additional migrant employment, but a high demand elasticity for chocolate discourages it. In fact one can show that the employment of foreign workers in the unfavorable state rises or falls according as the elasticity of substitution exceeds or falls short of that of demand.

\section{Concluding Remarks}

This paper has developed a theory of international trade and labor mobility built squarely upon the four stylized facts pointed to at the outset. The dominant theme is that of the smoothing out of native-labor employment fluctuations by means of a combination of commodity dumping and migrant dumping. It is the link between these two that in fact clarifies the seemingly inconsistent claims that the substitution of domestic labor for migrants allows unemployment to be exported and that the complementarity of the two types of labor permits cost reductions that sustain domestic employment. All this was shown to relate crucially to the stochastic nature of international markets and upon the relative magnitudes of elasticities of demand and of substitution. 
The present paper leans heavily on simplifying assumptions, because my prime concern has been to sketch out the essentials of a theory radically different from the standard one derived from factor-endowment trade models. 11 The need for further development should be obvious. Potential developments of greatest interest, in my judgment, include consideration of the effects of uncertainty of domestic origin, and also of the relation between migration and internal resource allocation and income distribution. It is often claimed that the ability to hire migrants reduces the need to reallocate native labor between sectors or between regions in response to changing circumstances. Analysis along these lines would entail the development of a mul.tisectoral version of the present model. Also of considerable interest would be the investigation of the consequences of asymetric access to information by domestic firms, native workers, and migrant laborers. 


\section{FOOTNOTES}

* This paper has been benefitted from comments during seminars at the universities of Pennsylvania and of Rochester, the Institute for International Economic Studies at Stockholm, and the Stockholm School of Economics.

1

An excellent general treatment of labor migration may be found in Piore [1979]. See Hiemenz and Schatz [1979] for details about foreign workers in Germany, Marshall [1973] for the Netherlands, Kennedy-Brenner [1979] for France, Corwin [1978] for Mexican migrants in the U.S. , Birks and Sinclair [1980] for the Middle East, and Zachariah and Conde [1981] for West Africa.

2 See Ohlin [1967, chpt. XVI], Corden [1955], Johnson [1965, chpt. III, Part III], Kemp [1969, chpt. 9], Markusen and Melvin [1979], Dixit and Norm an [1980, pp. 146-149], Bhagwati and Brecher [1980], Brecher and Bhagwati [1981], and Bhagwati [1979].

3 see the books mentioned in footnote 1, plus further references cited in those works.

4

W could instead be interpreted as collectively-supplied unemployment compensation. I do not describe it as such because I do not intend to investigate methods of financing it.

5 Justification for these assumptions is provided in the Appendix, although investigation of cases where they fail is straightforward.

6 See Ethier [1982] for a fuller, two-country theory of dumping.

7 Note the strong analogy with the Stolper-Samuelson theorem in factor-endowments models.

8 This follows from the algebra presented in the Appendix.

9

The Appendix shows that the conditions leading to this case are $\eta_{\mathrm{A}}=\sigma_{\mathrm{A}}=\sigma_{\mathrm{B}}=\eta_{\mathrm{B}}$.

${ }^{10}$ See Bhagwati [1968] and Bhagwati [1973] for the appropriate analogous treatment of immizerizing growth.

11 The present theory is actually closer in spirit to the dual economy models employed in development economics. See corden [1974, chpt. 6]. Of the references cited in footnote 2, Ohlin [1967] actually comes closest to the concerns of the present paper. 
REFERENCES

Azariadis, C., "Implicit Contracts and Underemployment Equilibria," Journal of political Economy, 83 (1975), 1183-1202.

Bhagwati, J.N., "Distortions and Immiserizing Growth: A Generalization," Review of Economic Studies 25 (1968), 201-205.

Bhagwati, J.N., "The Theory of Immiserizing Growth: Further Applications" in M.B. Connelly and A.K. Swoboda, International Trade and Money (Toronto: University of Toronto Press, 1973).

Bhagwati, J.N., "International Factor Movements and National Advantage," 9th V.K. Ramaswami Memorial Lecture, processed (1979).

Bhagwati, J. N. and R. A. Brecher, "National Welfare in an Open Economy in the Presence of Foreign-Owned Factors of Production," Journal of International Economies, 10 (1980), 103-116.

Birks, J. S. and C. A. Sinclair, International Migration and Development in the Arab Region (Geneva: International Labor Organization, 1980).

Brecher, R. A. and J. N. Bhagwati, "Foreign Ownership and the Theory of Trade and Welfare," Journal of Political Economy 89 (1981), 497-511.

Corden, W. M., "The Economic Limits to Population Increase," Economic Record, 31 (1955), 242-260.

Corden, W. M., Trade Policy and Economic Welfare (Oxford: Oxford University Press, 1974).

Corwin, A. F. (ed.), Immigrants - - and Immigrants: Perspectives on Mexican Labor Migration to the United States (Westport: Greenwood Press, 1978).

Dixit, A. and V. Norman, Theory of International Trade (London: Cambridge University Press, 1980).

Ethier, W. J., "Dumping," Journal of Political Economy 90 (1982).

Hiemenz, U. and K. W. Schatz, Trade in Place of Migration: An EmploymentOriented Study with Special Reference to the Federal Republic of Germany, Spain and Turkey (Geneva: International Labor Organization, 1979).

Johnson, H. G., International Trade and Economic Growth

(Cambridge: Harvard University Press, 1965).

Kemp, M. C., The Pure Theory of International Trade and Investment (Englewood Cliffs: Prentice Hall, 1969).

Kennedy-Brenner, C., Foreign Workers and Immigration Policy - - The Case of France (Paris: Organization for Economic Cooperation and Development, 1979).

Markusen, J. R. and J. R. Melvin, "Tariffs, Capital Mobility, and Foreign Ownership," Journal of International Economics, 9 (1979), 395-409. 
Marshall, A., The Import of Labour (Rotterdam: Rotterdam University Press, 1973).

Ohlin, B., Interregional and International Trade, revised edition (Cambridge: Harvard University Press, 1967).

Piore, M. J., Birds of Passage: Migrant Labour and Industrial Societies

(London: Cambridge University Press, 1979).

Zachariah, K. C. and J. Conde, Migration in West Africa: Demographic Aspects (New York: Oxford University Press, 1981). 


\section{APPENDIX}

A-I. Maximization and Equilibrium

This section shows how some of the assumptions used in the text can be derived from elementary implicit-contracts theory, as developed by Azariadis [1975]. Assume that (risk-averse) Swiss workers have identical, strictly concave utility functions over real income: $h\left(l_{0}\right)$. If $w_{i}$ denotes the wage paid in state $i$ and $e_{i}$ the probability of retaining a job should state $i$ actually materialize, the expected utility of the implicit contract $\left(w_{A}, w_{B}, e_{A}, e_{B}\right)$ is

(1A) $\frac{e_{A}}{2} h-\left(w_{A}\right)+\frac{e_{B}}{2} h-\left(w_{B}\right)+\left(1-\frac{e_{A}+e_{B}}{2}\right)-h-(w)=-u$

Competitive, risk-neutral firms maximize expected profit per contract, $\left(e_{A}\left[P_{A} f\left(x_{A}\right)-w_{A}-v_{A} x_{A}\right]+e_{B}\left[P_{B} f\left(x_{B}\right)-w_{B}-v_{B} x_{B}\right]\right) / 2$, for given $P_{A}, P_{B}, v_{A}$, and $v_{B}$, subject to the constraint that the expected utility of its contract, (1A), equal the prevailing market level. Decision variables are ${ }^{w}{ }_{A}, w_{B}, e_{A}, e_{B}, x_{A}$ and $x_{B}$. I assume that the identities of those workers to be laid off are determined by a random drawing among contracts once the state of the world is known. Thus $e_{i}$ equals the ratio of state $i$ employment to total contracts of the firm. Clearly $e_{A}$ and $e_{B}$ will not both be strictly less than unity, because offering superfluous contracts only reduces the utility to workers of all contracts. Assume $e_{B}=1$ without loss of generality.

The first order conditions for an internal solution to this problem are as follows:

$$
\begin{aligned}
& \mu h^{\prime}\left(w_{A}\right)-1=0 \\
& \mu h^{\prime}\left(w_{B}\right)-1=0
\end{aligned}
$$$$
P_{A} f\left(x_{A}\right)-w_{A}-v_{A} x_{A}+\mu\left[h\left(w_{A}\right)-h(w)\right]=0
$$

$$
P_{A} f^{\prime}\left(x_{A}\right)-v_{A}=0
$$


(6A)

$$
P_{B} f^{\prime}\left(x_{B}\right)-v_{B}=0
$$

together with (1A), for market-determined $u ; \mu$ is the multiplier associated with this constraint.

Conditions (2A) and (3A) imply that the firm offers a contract with a state invariant wage - - the basic result of elementary contract theory. Conditions (5A) and (6A) are (3) and (4) in the text. In market equilibrium, $u$ is endogenous and expected profits are driven to zero. Thus (1A) only measures $u$, but there is now the additional zero-profit condition

$$
e\left[\mathrm{P}_{A} f\left(x_{A}\right)-w-v_{A} x_{A}\right]+\left[P_{B} f\left(x_{B}\right)-w-v_{B} x_{B}\right]=0
$$

where $w \equiv w_{A}=w_{B}$ and $e \equiv e_{A} \cdot$ From (1A), define the utility of Swiss workers

$$
u(w, e)=\frac{1}{2}(1+e) h(w)+\frac{1}{2}(1-e) h(w) .
$$

With $\mathrm{V}$ (w, e) defined as $\mathrm{u}_{2} / \mathrm{u}_{1}$ we have

$$
V=\frac{h(w)-h(W)}{(1+e) h^{\prime}(w)}
$$

so that

$$
\begin{aligned}
& V_{w}=\frac{1}{1+e}-V \frac{h^{\prime \prime}(w)}{h^{\prime}(w)} \\
& V_{e}=-V /(1+e)
\end{aligned}
$$

which, together with the strict concavity of $h$, give (A1) and (A2) in the text. Condition ( $4 \mathrm{~A})$ can now be rewritten as

$$
P_{A} f\left(x_{A}\right)-w-v_{A} x_{A}+(1+e) V=0 .
$$

This gives equation (5) in the text. Substitution of the zero-profit condition $(7 \mathrm{~A})$ into (8A) gives $(6)$ in the text. 
A-II. Comparative Statics

Differentiation of (1) - (6) in the text results in the following:

$$
\hat{x}_{A}-n_{A} \hat{p}_{A}=\hat{e}+\hat{D}+\theta_{M A} \hat{x}_{A}
$$

(10A) $\quad \hat{\mathrm{X}}_{B}-\eta_{B} \hat{P}_{B}=\hat{D}+\theta_{M B} \hat{x}_{B}$

(11A) $\quad \theta_{D A} \hat{x}_{A}=\sigma_{A}\left(\hat{P}_{A}-\hat{v}_{A}\right)$

(12A) $\quad \theta_{D B} \hat{x}_{B}=\sigma_{B}\left(\hat{P}_{B}-\hat{v}_{B}\right)$

$(13 \mathrm{~A})$

$$
\frac{{ }_{D A}{ }^{\theta} M A}{\sigma_{A}} \hat{x}_{A}=\gamma_{A} \hat{w}-\theta_{D A} \hat{P}_{A}
$$

$(14 \mathrm{~A})$

$$
\frac{{ }^{\theta}{ }_{D B}{ }^{\theta} M B}{\sigma_{B}} \hat{x}_{B}=\gamma_{B} \hat{w}-\theta_{D B} \hat{P}_{B}+\left(\theta_{D B}-\mu_{D B}\right) \hat{e}
$$

All comparative statics results in the text involve manipulation of these six equations. To derive the properties of the various curves in Figure 2, set $\hat{x}_{B}=\hat{v}_{B}=\hat{D}=0$. Then (9A), (11A), (13A) and (14A) give

$$
\begin{array}{ll}
(e=1 ; \hat{e}=0) & \hat{x}_{A}=\left(\eta_{A}-\sigma_{A}\right) \theta_{M A} \hat{v}_{A} \\
\left(P_{A}=P_{B} ; \hat{P}_{A}=0\right) & \hat{x}_{A}=-\theta_{M A}\left[\frac{\sigma_{A}}{\theta_{D A}}-\frac{\gamma_{B}}{\gamma_{A}} \frac{1}{\theta_{D B}-\mu_{D B}}\right] \hat{v}_{A}
\end{array}
$$$$
\left(m=e ; \hat{x}_{A}=0\right) \quad \hat{x}_{A}=\left[\eta_{A}-\frac{\gamma_{B}}{\gamma_{A}} \frac{\theta_{D A}}{\theta_{D B}-\mu_{D B}}\right] \hat{v}_{A}
$$$$
\left(m=1 ; \hat{e}+\hat{x}_{A}=0\right) \quad \hat{x}_{A}=\left[\eta_{A}-\frac{\gamma_{B}}{\gamma_{A}} \frac{\theta_{D A}}{\theta_{D B}-\mu_{D B}} \frac{\sigma_{A}-\eta_{A}}{\frac{\sigma_{A}}{\theta_{D A}}-\frac{\gamma_{B}}{\gamma_{A}} \frac{1}{\theta_{D B}-\mu_{D B}}}\right] \hat{v}_{A} \text {. }
$$

Thus the slope of the $e=1$ line depends upon the sign of $\eta_{A}-\sigma_{A}$, the $P_{A}=P_{B}$ 
line has negative slope, and the $m=e$ and $m=1$ lines both have positive slopes, with the latter the steeper. In the special case $n_{A}=\sigma_{A}$, the $e=1$ line is flat and the elasticity of $\mathrm{m}=1$ is the elasticity of demand.

As a second comparative statics exercize, consider a general rise in migrant wages: $\hat{v}_{A}=\hat{v}_{B}=\hat{v}_{\text {. }}$ Let $\hat{x}_{A}=\hat{x}_{B}=\hat{D}=0$ in (9A)-(14A) and solve for the endogenous variables. This gives the following

(15A) $\hat{\mathrm{P}}_{\mathrm{A}}=\frac{{ }_{\mathrm{DA}} \gamma_{\mathrm{A}}}{\mathrm{Z}}\left[\left(\theta_{\mathrm{DB}}-\mu_{\mathrm{DB}}\right) \theta_{\mathrm{MA}}\left(\sigma_{\mathrm{A}}-\eta_{\mathrm{A}}\right)-\frac{\theta_{\mathrm{DB}}{ }^{\theta} \mathrm{MB}}{\rho_{\mathrm{A}}}\left(\sigma_{\mathrm{B}}-\eta_{\mathrm{B}}\right)+\frac{\mathrm{Z}}{\theta_{\mathrm{DA}}{ }_{\mathrm{A}}}\right] \hat{\mathrm{v}}$ (16A) $\hat{\mathrm{P}}_{B}=\frac{\hat{\theta}_{M B} \sigma_{B}}{\rho_{B}} \hat{v}$

(17A) $\hat{M}=-\frac{\eta_{B} \sigma_{B}}{\rho_{B}} \hat{v}$

$(18 A) \hat{e}=\left(\frac{1}{Z_{\rho_{B}}}\right)\left[\theta_{M B} \theta_{D B}{ }_{A}^{\rho} A\left(\sigma_{B}-\eta_{B}\right)-\theta_{M A} \theta_{D A}{ }_{B} \rho_{B}\left(\sigma_{B}-\eta_{A}\right)\right] \hat{v}$ $\hat{\mathrm{w}}=\left(\frac{1}{\mathrm{Z} \rho_{\mathrm{B}}}\right)\left[{ }_{\mathrm{DA}}{ }_{\mathrm{MA}}\left(\theta_{\mathrm{DB}}-\mu_{\mathrm{DB}}\right) \rho_{\mathrm{B}}\left(\sigma_{\mathrm{A}}-\bar{\eta}_{\mathrm{A}}\right)-{ }_{\mathrm{DB}} \theta_{\mathrm{MB}}{ }^{\theta} \mathrm{DA}\left(\sigma_{\mathrm{B}}-\bar{\eta}_{\mathrm{B}}\right)\right] \hat{\mathrm{v}}$

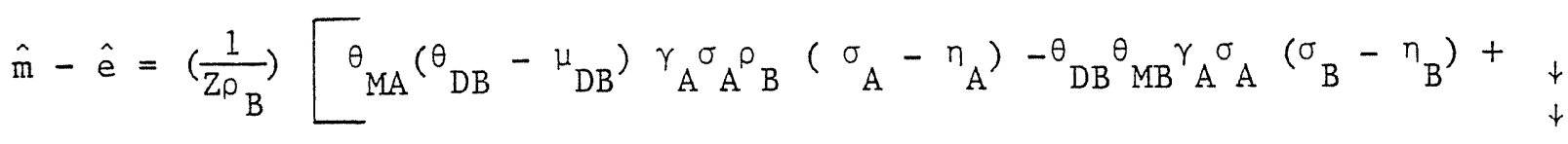

$$
\left.Z\left(n_{B} \sigma_{B}-\rho_{B} \sigma_{A}\right)\right] \hat{v}
$$

where $M$ denotes the employment of migrants in state $B$, and $\mathrm{Z}=\rho_{\mathrm{A}}\left(\theta_{\mathrm{DB}}-\mu_{D B}\right) \gamma_{A}-\theta_{D A} \gamma_{B}<0$. If $\hat{\mathrm{V}}>0$, then $\mathrm{P}_{\mathrm{B}}$ increases and $\mathrm{M}$ falls. The direction of change of all other terms is ambiguous, with e rising or falling as $\sigma_{A}$ exceeds or falls short of $\eta_{A}$; the other terms are all sensitive to the sizes of these elasticities as well as to various shares. In the special case 
$(A-5)$

$$
\begin{aligned}
& n_{A}=\sigma_{A}=\sigma_{B}=n_{B} \text { these equations give: } \\
& \hat{M}<0 ; \hat{P}_{A}=\hat{v}>\theta_{M B} \hat{v}=\hat{P}_{B}>0, \hat{e}=\hat{m}=\hat{w}=0 .
\end{aligned}
$$

